\title{
Accuracy of Fine Needle Aspiration Cytology in Head and Neck Masses
}

\author{
V. K. Poorey $\cdot$ Amit Tyagi
}

Received: 18 January 2014/ Accepted: 1 February 2014/Published online: 14 February 2014

(C) Association of Otolaryngologists of India 2014

\begin{abstract}
In ENT clinical practice patients with neck swelling is a common presentation. To know their exact nature a simple, sensitive and diagnostic tool is required to prevent unnecessary costlier investigation and corresponding treatment. Fine needle aspiration cytology (FNAC) is a very safe, sensitive and diagnostic tool. This study was done to know the diagnostic accuracy, sensitivity and specificity of the FNAC in head and neck masses. Present prospective study was done in 179 patients of head and neck masses which were subjected to FNAC and their results were later correlated with histopathological examination report (HPR) wherever available. Out of 179 FNAC, HPR available only in 152 cases. In present study 104 cases $(58.10 \%)$ of lymph node, 35 cases $(19.55 \%)$ of thyroid gland, 17 cases $(9.49 \%)$ of salivary gland, 12 cases $(6.70 \%)$ of soft tissue and 11 cases $(6.14 \%)$ of miscellaneous swellings were present. The sensitivity, specificity, positive predictive value and negative predictive value of present study were $81.8,95.0,81.8$ and $95.0 \%$ respectively. The accuracy was $92.10 \%$.
\end{abstract}

Keywords FNAC - Histopathological examination report (HPR) $\cdot$ Neck masses

V. K. Poorey $(\bowtie) \cdot$ A. Tyagi

Department of ENT and Head and Neck Surgery,

Gandhi Medical College and Hamidia Hospital,

Bhopal 462001, MP, India

e-mail: drvkpoorey@gmail.com

A. Tyagi

e-mail: amitdj82@gmail.com

\section{Introduction}

Neck swelling is a very common clinical presentation in routine ENT clinical practice. These swelling due to their superficial nature can be easily subjected to diagnostic procedure which is advantageous to both doctor and the patient. Good patient acceptability, repeatability and avoidance of unnecessary surgical procedure made FNAC as a popular investigation. This tool can easily differentiate benign from malignant swellings and avoid unnecessary investigation which the patient has to undergo for the final diagnosis on which management depends. The expansion of FNAC in primary diagnosis of tumors in the last 30 years or so has been impressive and generally successful. This development is to a large degree the result of consistent, continuous and critical correlation between cytological assessment and histopathological diagnosis facilitated by the organizational coordination of laboratory resources. Though the first utilization of FNAC was done in St. Bartholomew's Hospital [14] but it was Kunn [12] who, for the first time used cutting edge needle for taking material from subcutaneous tumours and did cytological smear analysis. Grieg and Gray [7] aspirated swollen lymph node by a needle and syringe from patients with sleeping sickness to identify the mobile trypanosomes. Guthrie [8] (1921) described how aspirates obtained from lymph node helped to diagnose various causes of lymphadenopathy. Frable et al. [4] performed thin needle aspiration biopsy in 84 patients with head and neck masses. There were 53 cases of lymph nodes, ten salivary gland lesion and ten were of thyroid masses. In his study 37 were found to be benign and 40 were malignant, four were false negative cases reported whereas no false positive cases were encountered. They concluded that fine needle aspiration cytology to be quiet accurate in diagnosis of head and neck masses. 


\section{Methods}

The present study aims at pointing out the diagnostic utility of the fine needle aspiration in head and neck masses. This study is undertaken from June 2012-November 2013 in the Department of ENT in Gandhi Medical College and Hamidia Hospital, Bhopal in 179 patients. Inclusive criteria all the patients attending ENT OPD at Hamidia Hospital having head and neck masses irrespective of age and sex, who. FNAC was performed in 179 patients who had head and neck lumps, the results of which were analyzed and compared with HPR wherever available. The hypocellular/ acellular smear, previously had FNAC/surgery/biopsy and proven cases of malignant or nonmalignant lesion were excluded from the study. In present study HPR available in only 152 cases for cytocorrelation. In two cases FNAC reports came as inconclusive and in twenty-five cases no histopathological examination was done.

\section{Results}

Present study includes 179 cases, in which 95 cases $(53.07 \%)$ were females while males were 84 (46.93\%). In our study more number of female cases was present. The maximum number of cases was reported in the 21-30 years of age group which were $44(24.58 \%)$. The youngest patient in the series was 2 years old and the oldest was 80 years of age. The mean age was 32 years. Out of 179 cases, 104 cases $(58.10 \%)$ were of lymph node, 35 cases $(19.55 \%)$ of thyroid gland, 17 cases $(9.49 \%)$ of salivary gland, 12 cases $(6.70 \%)$ of soft tissue and 11 cases $(6.14 \%)$ of miscellaneous groups present. The maximum and minimum number of cases was reported from lymph node and miscellaneous group respectively. Two cases were reported as inconclusive on FNAC comprising follicular neoplasm which later confirmed as follicular carcinoma on subsequent HPR as cytology cannot differentiate between benign and malignant follicular neoplasm. Out of 177 cases, cytological diagnosis revealed maximum number of cases comprise of inflammatory 78 cases $(44.06 \%)$, followed by benign 66 cases $(37.29 \%)$ and malignant 33 cases (18.64\%) respectively. Amongst males maximum number of cases were benign 30 cases $(16.94 \%)$ while in females were inflammatory 51 cases $(28.81 \%)$. The malignant cases were more in males 27 cases $(15.25 \%)$ while benign cases were more in females 36 cases $(20.33 \%)$. The females reported only 6 cases $(3.39 \%)$ as malignant which was least amongst the all masses. Out of 104 cases of lymph node masses 10 cases were found to be the inflammatory on cytology where HPR was not available, so they were excluded from the study. Amongst the remaining 94 cases, majority were found to be tubercular 32 cases $(34.04 \%)$. The rest of the cases comprise of reactive node 17 cases $(18.08 \%)$, non-specific inflammation 20 cases $(21.28 \%)$, metastatic 20 cases (21.28) and lymphoma 5 cases (5.32\%). Out of 35 cases of thyroid swelling maximum number of cases were found to be of colloid goitre 19 cases $(54.28 \%)$, followed by inflammatory 12 cases $(34.28 \%)$ and follicular neoplasia 2 cases $(5.71 \%)$, papillary carcinoma 1 case $(2.85 \%)$ and multinodular goitre 1 case $(2.85 \%)$ respectively. Only 17 cases of salivary gland swellings were reported. The maximum no. of cases belongs to pleomorphic adenoma 6 cases $(35.29 \%)$ and sialadenitis 6 cases $(35.29 \%)$ respectively. The remaining cases were comprised of inflammatory 3 cases $(17.65 \%)$, adenoid cystic carcinoma 1 case $(5.88 \%)$ and warthins tumour 1 case $(5.88 \%)$ respectively. Out of 12 total cases reported of soft tissue swelling, majority cases comprise of sebaceous cyst 8 cases $(66.66 \%)$, amongst remaining 4 cases 1 case $(8.33 \%)$ each was represented by lipoma, cystic lesion, lymphangioma and retention cyst respectively. Amongst 11 cases of miscellaneous swellings majority were represented by squamous cell carcinoma 6 cases $(54.54 \%)$, rest of the cases comprise of branchial cyst 2 cases $(18.18 \%$ ), thyroglossal cyst 2 cases $(18.18 \%)$ and hemorrhagic vascular lesion 1 case $(9.09 \%)$ respectively.

As per Table 1, out of 78 cases $(44.07 \%)$ of inflammatory swellings majority were comprised by lymph node 63 cases $(35.60 \%)$, followed by thyroid swelling 12 cases $(6.78 \%)$ and salivary gland 3 cases $(1.70 \%)$. Not even a single case was found among soft tissue and miscellaneous swelling which was inflammatory in nature. Amongst 66cases $(37.29 \%)$ of benign swelling majority of cases belongs to thyroid gland 20 cases $(11.30 \%)$, followed by lymph node 16 cases $(9.04 \%)$, salivary gland 13 cases (7.34 \%), soft tissue 12 cases $(6.78 \%)$ and miscellaneous 5 cases $(2.82 \%)$ respectively. In 33 cases $(18.64 \%)$ of malignant lesion maximum number belongs to lymph node 25 cases $(14.12 \%)$, next in frequency was miscellaneous lesions 6 cases $(3.39 \%)$ followed by 1 case $(0.56 \%)$ each by thyroid gland and salivary gland. No malignancy was reported amongst soft tissue lesion.

As per Table 2, out of total 104 cases of lymph node HPR was present only in 94 cases so in 10 cases $(9.61 \%)$ cytological correlation with histopathology could not be done. Amongst 17 cases of reactive lymph node lesions, two cases were found where HPR differ from FNAC and their diagnosis later found to be Non Hodgkin lymphoma and constitute as false negative. Amongst 20 cases of inflammatory lesion cytocorrelation was absent in one case which found to be metastatic squamous cell carcinoma and considered as false negative. In tubercular lesion $100 \%$ correlation was present. In 20 cases of metastatic lesion one case was found to be false positive which later identified on histopathology 
Table 1 Organ wise cytological diagnosis distribution of cases

\begin{tabular}{|c|c|c|c|c|c|c|}
\hline \multirow[t]{3}{*}{ Site of lesion } & \multicolumn{6}{|c|}{ Cytological diagnosis } \\
\hline & \multicolumn{2}{|l|}{ Inflammatory } & \multicolumn{2}{|l|}{ Benign } & \multicolumn{2}{|l|}{ Malignat } \\
\hline & No. of cases & Percentage $(\%)$ & No. of cases & Percentage $(\%)$ & No. of cases & Percentage $(\%)$ \\
\hline Lymph node & 63 & 35.6 & 16 & 9.04 & 25 & 14.12 \\
\hline Thyroid gland & 12 & 6.78 & 20 & 11.3 & 1 & 0.56 \\
\hline Salivary gland & 3 & 1.7 & 13 & 7.34 & 1 & 0.56 \\
\hline Soft tissue & - & - & 12 & 6.78 & - & - \\
\hline Miscellaneous & - & - & 5 & 2.82 & 6 & 3.39 \\
\hline Total & 78 & 44.07 & 66 & 37.29 & 33 & 18.64 \\
\hline
\end{tabular}

as tubercular. In five cases of lymphoma cytocorrellation was absent in two cases which labelled as false positive as they found to be tubercular and reactive hyperplasia respectively and considered as benign in nature. Amongst lymph node three cases were found to be false negative and three cases were found to be false positive.

Out of 17 cases of salivary gland lesion cytocorrelation was present only in 14 cases, amongst which cytocorrelation was exactly similar to histopathological diagnosis in 12 cases. In two cases cytocorrrelation differ in which one case diagnosed as pleomorphic adenoma on cytology was found to be mucoepidermoid carcinoma on histological examination and considered as false negative. The other case was diagnosed as adenoid cystic carcinoma on cytology later found to be pleomorphic adenoma on histology and considered as false positive.

Table 2 Organ wise FNAC diagnosis correlation with HPR diagnosis

\begin{tabular}{lllll}
\hline FNAC & \multicolumn{4}{l}{ Correlation } \\
diagnosis & Toth HPR diagnosis & \\
\cline { 2 - 4 } $\begin{array}{l}\text { of organ } \\
\text { involved }\end{array}$ & no. $(\%)$ & Present & Absent & Not \\
& & & $(\%)$ & $\begin{array}{l}\text { available } \\
(\%)\end{array}$
\end{tabular}

\begin{tabular}{|c|c|c|c|c|}
\hline \multicolumn{5}{|l|}{ Lymph node } \\
\hline Reactive & 17 & 15 & $2(2 \mathrm{FN})$ & - \\
\hline Inflammatory & 30 & 19 & $1(\mathrm{FN})$ & 10 \\
\hline Tubercular & 32 & 32 & - & - \\
\hline Metastatic & 20 & 19 & $1(\mathrm{FP})$ & - \\
\hline Lymphoma & 5 & 3 & $2(2 \mathrm{FP})$ & - \\
\hline Salivary gland & 17 & 12 & $2(\mathrm{FP}, \mathrm{FN})$ & 3 \\
\hline Thyroid gland & 35 & 18 & 3 & $12+2 *$ \\
\hline Soft tissue & 12 & 12 & - & - \\
\hline Miscellaneous & 11 & 10 & $1(\mathrm{FP})$ & - \\
\hline Total cases & $\begin{array}{l}179 \\
\quad(100 \%)\end{array}$ & $\begin{array}{l}140 \\
(78.21 \%)\end{array}$ & $12(6.70 \%)$ & $\begin{array}{l}27 \\
\quad(15.08 \%)\end{array}$ \\
\hline & & $152(84.91 \%$ & & \\
\hline
\end{tabular}

$F N$ false negative, $F P$ false positive, $2 *$ inconclusive
Out of 35 cases of thyroid swelling cytological correlation was present in 21 cases. In two cases though cytology was done and diagnosed as follicular neoplasm but inference was inconclusive so correlation could not be possible. Both these cases later found to be follicular carcinoma on histopathology. In 12 inflammatory cases HPR not available so correlation could not be done. Amongst 21 cases where HPR available, three cases were found where cytocorrelation differ. One case was considered as false positive as was diagnosed on cytology as papillary carcinoma but later on histopathology found to be colloid goitre. Two cases of colloid goitre later diagnosed on histopathology as papillary carcinoma and considered as false negative.

Statistical analysis was done using Statistical Product and Service Solutions 16 software and EPI MAX calculator for calculating different statistical parameters which are as follows: sensitivity $81.8 \%$, specificity $95.0 \%$, positive predictive value $81.8 \%$, negative predictive value $95.0 \%$ and accuracy of $92.10 \%$ as per Table 3 .

\section{Discussion}

In present study number of female cases were greater than males and male to female ratio was found to be $1: 1.13$. Mean age was 32 years, youngest patient was 2 years old and the oldest was 80 years of age in the series. The most patients belong to the 21-30 years of age group. All 179 cases were analyzed with their history, clinical presentation, fine needle aspiration cytology findings and histopathology. Out of these 179 patients, FNAC revealed 78 cases $(44.06 \%)$ as inflammatory and 66 cases $(37.29 \%)$ as benign thus constitute an overall 144 cases $(81.35 \%)$ as nonmalignant masses. In case of benign lesion present study corresponds to the study of Frable et al. [5]. Out of 179 cases in 25 cases HPR not available so they were finally excluded from correlation analysis. The malignant cases were 33 in number and constitute $18.64 \%$ of the 
total cases. In two cases (1.12\%) FNAC diagnosis was inconclusive (follicular neoplasia) so they were also excluded from cytocorrelation analysis and constituted as indeterminate. In the present study on head and neck masses reported cases are as follows 35 cases of thyroid, 17 cases of salivary gland, 104 cases of lymph node and 11 cases of miscellaneous swellings. Present study corresponds to the study done by Smallman et al. [16] and O'Donnell et al. [13]. In the present study percentage of reactive lymphadenitis cases were $18.08 \%$. Present study corresponds to Muhammad Javaid et al. [10] in which he reported case percentage as $16.66 \%$. In the present study total number of lymph node aspirated 94 which are also available for cytocorrelation and number of tubercular lymph node found to be 32 (34.04\%). Our results corresponds to Patra et al. [15] in which he aspirated 113 cases and found 34 cases of tubercular lymph node amounts to $30.01 \%$. In the present study 5 cases of lymphoma were reported out of 94 total case amounts to $5.32 \%$. Our study corresponds to Hag et al. [2] in which he reported 9 cases of lymphoma out of 225 lymph node aspirated and amounts to $4 \%$. Out of 12 total case reported of soft tissue swelling, majority cases comprise of Sebaceous cyst 8 cases $(66.66 \%)$, amongst remaining 4 cases 1 case $(8.33 \%)$ each was represented by Lipoma, Cystic lesion, Lymphangioma and Retention cyst respectively. All the cases were benign in this series. No malignant case found even on histopathological examination and FNAC diagnosis match with the histological diagnosis amounting to $100 \%$ accuracy in diagnosing soft tissue lesion. No similar study could be found for correlation with our study. Eleven cases $(6.14 \%)$ were reported in the group of miscellaneous lesions. Authors found 6 cases $(54.54 \%)$ of Squamous cell carcinoma, 2 cases $(18.18 \%$ ) each of Branchial cyst and Thyroglossal cyst and 1 case $(9.09 \%)$ of Hemorrhagic lesion on FNAC which later found to be Hemangioma on histopathological examination. One case found to be false positive in this series. The clinical diagnosis of Branchial sinus found to be Squamous cell carcinoma in FNAC which later found to be Branchial fistula in histopathology. A lymph node metastasis of well-differentiated squamous cell carcinoma with liquefactive necrosis is a very important and often difficult differential diagnosis of branchial cyst. Conversely, atypical reactive and metaplastic squamous cell in smears from an inflamed branchial cyst can sometimes cause concern. No similar study was available for correlation with our study. In the present study 35 cases of thyroid swelling were reported, in which $11.30 \%$ are benign, $0.56 \%$ were malignant and $2 \%$ were inconclusive. Present study did not corresponds to other study done on thyroid, the possible explanation of that could be because of small sample size, only 21 cases were available for cytocorrelation and 2 cases were reported as inconclusive which later found to be follicular carcinoma also only one case of papillary carcinoma was reported. Two cases of colloid goiter reported on FNAC later found to be papillary carcinoma and labelled as false negative while one case of papillary carcinoma later on histopathology found to be colloid goiter and labelled as false positive. Groups of large cells with irregular nuclei are not infrequently found in nodular goiter and are probably related to degenerative change. Their origin is uncertain; they may be histiocytes or regenerating epithelial cells consistent with repair. Prominent aggregates of histiocytes can in some cases mimic cells of papillary thyroid carcinoma due to similar nuclear features. In present study out of total 17 cases of salivary gland $7.34 \%$ were benign and $0.56 \%$ as malignant. Here also our study did not corresponds to other studies probably again because of very small sample size and in three cases histopathological report not available for cytocorrelation. Only one case of malignancy adenoid cystic carcinoma was reported. The pleomorphic adenoma was the most common lesion in 7 cases. One case of adenoid cystic carcinoma later found to be pleomorphic adenoma and labelled as false positive. Both tumours have relatively uniform epithelial-like cells and both may have a fibrillar myxoid stromal component. Hyaline stromal globules resembling those characteristic of adenoid cystic carcinoma or a beaded hyaline stromal can sometimes be found in pleomorphic adenoma. One case of pleomorphic adenoma later found to be mucoepidermoid carcinoma and labelled as false negative. Low grade mucoepidermoid carcinoma is one of the most difficult entities to diagnose cytologically and is a source of false negative diagnoses even in surgical pathology. The main reason is that many tumours are partly or predominantly cystic. The aspirated material is often hypocellular and non- characteristic, consisting mainly of mucoid secretion, debris and some inflammatory cells. In present study, there was $81.81 \%$ sensitivity and $94.96 \%$ specificity and with a
Table 3 FNAC diagnosis correlation with HPR diagnosis

$T P$ true positive, $T N$ true negative, $F P$ false positive, $F N$ false negative

\begin{tabular}{llcr}
\hline HPR diagnosis & \multicolumn{2}{l}{ FNAC diagnosis } & \\
\cline { 2 - 4 } & \multicolumn{1}{l}{ Malignant } & Non-malignant & \multicolumn{1}{c}{ Total } \\
\hline Malignant & $27(17.76 \%)(\mathrm{TP})$ & $6(3.94 \%)(\mathrm{FN})$ & $33(21.71 \%)$ \\
Non-malignant & $6(3.94 \%)(\mathrm{FP})$ & $113(74.34 \%)(\mathrm{TN})$ & $119(78.29 \%)$ \\
Total & $33(21.71 \%)$ & $119(78.29 \%)$ & $152(100 \%)$ \\
\hline
\end{tabular}


Table 4 Study of FNAC by various authors and their statistical parameters

\begin{tabular}{llcc}
\hline Authors & $\begin{array}{l}\text { Accuracy } \\
\text { rate }(\%)\end{array}$ & $\begin{array}{l}\text { Sensitivity } \\
(\%)\end{array}$ & $\begin{array}{l}\text { Specificity } \\
(\%)\end{array}$ \\
\hline Tilak et al. [17] & 92.7 & 90.9 & 93.2 \\
Klemi et al. [11] & 95.0 & 55.0 & 100 \\
Gharib et al. [6] & 95.0 & 83.0 & 92.0 \\
Fernandes et al. [3] (2009) & 87.5 & 90.3 & 80.0 \\
Balakrishnan et al. [1] & 83.0 & 79.0 & 84.0 \\
Hussain et al. [9] & 95.0 & 100.0 & 98.0 \\
Present study (2014) & 92.10 & 81.81 & 94.96 \\
\hline
\end{tabular}

diagnostic accuracy of $92.10 \%$ compared to other studies (Table 4).

\section{Conclusion}

FNAC is a simple, safe, cost-effective, sensitive and specific technique in the initial evaluation of head and neck mass. FNAC offers an advantage in diagnosis of neoplastic and non- neoplastic lesions. There was almost good $(92.11 \%)$ agreement between the cytological and histological findings in the present study and fairly good accuracy. There were six false negatives and six false positives in our study amounts to $(7.89 \%)$. Hence, we conclude that Fine Needle Aspiration Cytology is a highly effective diagnostic procedure in the diagnosis and management of palpable head and neck masses.

\section{References}

1. Balakrishnan K, Castling B, Mc Mahon J, Imrie J, Feeley KM, Parker AJ, Bull PD, Johnston A (2005) Fine needle aspiration cytology in the management of a parotid mass: a two centre retrospective study. Surgeon 3(2):67-72. doi:10.1016/S1479666X(05)80064-2

2. El Hag IA, Chiedozi LC, Al Revees FA (2003) Fine needle aspiration cytology of head and neck masses: seven year experience in a secondary care hospital. Acta Cytol 47(3):387-392

3. Fernandes GC, Pandit AA. Diagnosis of salivary gland tumors by FNAC 2005 (MEDLINE)

4. Frable WJ, Frable MA (1974) Thin needle aspiration in the diagnosis of head and neck tumours. Laryngoscope 84: 1069-1077

5. Frable MA, Frable WJ (1982) Fine-needle aspiration biopsy revisited. Laryngoscope 92(12):1414-1418

6. Gharib H, Goellner JR (1993) Fine-needle aspiration biopsy of the thyroid; an appraisal. Ann Int Med 118:282-289

7. Grieg ED, Gray AC (1904) Lymphatic gland in sleeping sickness. Br Med J 1:1252

8. Guthrie CG (1921) Gland puncture as a diagnostic measure. Bull Johns Hopkins Hosp 32:266

9. Hussain N, Sheikh AS, Bokhari MH, Naveed IA (2002) The value of fine needle aspiration cytology in the diagnosis of lymphodenopathy. Biomedica 18:38-40

10. Javaid M, Niamatullah, Anwar K, Said M (2006) Diagnostic value of fine needle aspiration cytology in cervical lymphadenopathy. JPMI 20:117-120

11. Klemi PJ, Joensuu H, Nylamo E (1991) Fine needle aspiration biopsy in the diagnosis of thyroid nodules. Acta Cytol 35(4): 434-869

12. Kun M (1846) a new instrument for diagnosis of tumours. Mon $\mathbf{J}$ med sci 7:853

13. O' Donnell ME, Salem A, Badger SA et al (2009) Fine needle aspiration at a regional head and neck clinic: a clinically beneficial and cost-effective service. Cytopathology 20:81-86

14. Patil SY, Malipatil RA (2012) Histoid leprosy: role of fine needle aspiration cytology in the diagnosis. J Sci Soc 39:141-143

15. Patra AK, Nanda BK, Mohapatra BK, Panda AK (1983) Diagnosis of lymphadenopathy by fine needle aspiration cytology. Indian J Pathol Microbiol 26:273-278

16. Smallman LA, Young JA, Oates J, Proops DW, Johnson AP (1988) Fine needle aspiration cytology in the management of ENT patients. J Laryngol Otol 102:909-913

17. Tilak V, Dhaded AV, Jain R (2002) Fine needle aspiration cytology of head and neck masses. Indian J Pathol Microbiol 45(1):23-29 